\title{
Health related quality of life six months following surgical treatment for secondary peritonitis - using the EQ-5D questionnaire
}

Kimberly R Boer*1, Oddeke van Ruler ${ }^{2}$, Johannes B Reitsma ${ }^{1}$, Cecilia W Mahler ${ }^{2}$, Brent C Opmeer ${ }^{1}$, E Ascelijn Reuland ${ }^{2}$, Hein G Gooszen ${ }^{3}$, Peter W de Graaf ${ }^{4}$, Eric J Hesselink ${ }^{5}$, Michael F Gerhards 6 , E Philip Steller ${ }^{7}$, Mirjam A Sprangers ${ }^{8}$, Marja A Boermeester ${ }^{2}$, Corianne A De Borgie ${ }^{1}$ and The Dutch Peritonitis Study Group ${ }^{9}$

Address: ${ }^{1}$ Department of Clinical Epidemiology, Biostatistics and Bioinformatics, Academic Medical Center, Amsterdam, The Netherlands, 2Department of Surgery, Academic Medical Center Amsterdam, The Netherlands, ${ }^{3}$ Department of Surgery, University Medical Center Utrecht, Utrecht, The Netherlands, ${ }^{4}$ Department of Surgery, Reinier de Graaf Hospital, Delft, The Netherlands, ${ }^{5}$ Department of Surgery, Gelre Hospital, Apeldoorn, The Netherlands, ${ }^{6}$ Department of Surgery, Onze Lieve Vrouwe Gasthuis, Amsterdam, The Netherlands, ${ }^{7}$ Department of Surgery, Sint Lucas Andreas Hospital, Amsterdam, The Netherlands, ${ }^{8}$ Department of Medical Psychology, Academic Medical Center Amsterdam, The Netherlands and ${ }^{9}$ Department of Surgery, Academic Medical Center Amsterdam, The Netherlands

Email: Kimberly R Boer* - k.r.boer@amc.nl; Oddeke van Ruler - o.vanruler@amc.nl; Johannes B Reitsma - j.reitsma@amc.nl; Cecilia W Mahler - cwmahler@hotmail.com; Brent C Opmeer - b.c.opmeer@amc.nl; E Ascelijn Reuland - e.reuland@amc.nl; Hein G Gooszen - H.Gooszen@umcutrecht.nl; Peter W de Graaf - PWGraaf@rdgg.nl; Eric J Hesselink - hesse@gelre.nl;

Michael F Gerhards - m.f.gerhards@olvg.nl; E Philip Steller - e.steller@slaz.nl; Mirjam A Sprangers - m.a.sprangers@amc.nl; Marja A Boermeester - m.a.boermeester@amc.uva.nl; Corianne A De Borgie - c.deborgie@amc.nl; The Dutch Peritonitis Study Group - k.r.boer@amc.nl

* Corresponding author

Published: 2 July 2007

Health and Quality of Life Outcomes 2007, 5:35 doi:10.1 I86/1477-7525-5-35

This article is available from: http://www.hqlo.com/content/5/1/35

(c) 2007 Boer et al; licensee BioMed Central Ltd.

This is an Open Access article distributed under the terms of the Creative Commons Attribution License (http://creativecommons.org/licenses/by/2.0), which permits unrestricted use, distribution, and reproduction in any medium, provided the original work is properly cited.
Received: 13 April 2007

Accepted: 2 July 2007

\begin{abstract}
Background: To compare health related quality of life (HR-QoL) in patients surgically treated for secondary peritonitis to that of a healthy population. And to prospectively identify factors associated with poorer (lower) HR-QoL.

Design: A prospective cohort of secondary peritonitis patients was mailed the EQ-5D and EQVAS 6-months following initial laparotomy.

Setting: Multicenter study in two academic and seven regional teaching hospitals.

Patients: 130 of the 155 eligible patients (84\%) responded to the HR-QoL questionnaires.

Results: HR-QoL was significantly worse on all dimensions in peritonitis patients than in a healthy reference population. Peritonitis characteristics at initial presentation were not associated with HR-QoL at six months. A more complicated course of the disease leading to longer hospitalization times and patients with an enterostomy had a negative impact on the mobility $(p=0.02)$, self-care $(p<0.00 \mathrm{I})$ and daily activities: $(p=0.0 \mathrm{I})$. In a multivariate analysis for the EQ-VAS every doubling of hospital stay decreases the EQ-VAS by 3.8 points $(p=0.015)$. Morbidity during the six-month follow-up was not found to be predictive for the EQ-5D or EQ-VAS.
\end{abstract}


Conclusion: Six months following initial surgery, patients with secondary peritonitis report more problems in HR-QoL than a healthy reference population. Unfavorable disease characteristics at initial presentation were not predictive for poorer HR-QoL, but a more complicated course of the disease was most predictive of HR-QoL at 6 months.

\section{Background}

Secondary peritonitis has a high in-hospital mortality (24-35\%), continued high post-hospital discharge mortality, as well as a considerable long-term morbidity [1-5]. Patients are hospitalized for extensive periods of time and often endure lengthy intensive care unit (ICU) stays [512].

Recently, improving Health Related Quality of Life (HRQoL) in patients with sepsis $[11,13,14]$ has become a complementary goal in patient care [15]. The importance of HR-QoL will continue to grow with improvement in peritonitis survival. Till now, most HR-QoL data in secondary peritonitis and abdominal sepsis have been collected retrospectively $[4,13,14,16,17]$. These studies have shown that peritonitis patients suffer from HR-QoL impairments both in the short-term as well as the longterm. Good quality data from prospective studies are necessary to identify factors related to lower HR-QoL. Insight into these factors is needed to inform patients, to develop preventive measures for high-risk patients, and to provide tailored support for individual patients.

The aims of this study were twofold. Firstly, to assess HRQoL in patients with secondary peritonitis, and to compare this with HR-QoL reported for a general reference population [18]. And secondly, to determine which factors (patient, peritonitis and postoperative) are related to HR-QoL six months following patients with severe secondary peritonitis (APACHE II > 10) $[19,20]$.

\section{Methods \\ Study design}

This study was embedded in an ongoing peritonitis trial evaluating two surgical strategies for patients with peritonitis, initiated by the Academic Medical Center (AMC), Amsterdam, The Netherlands. Patients were enrolled between December 2001 and August 2005 in 2 academic and 7 regional teaching hospitals in The Netherlands.

\section{Patients}

Patients were eligible for the RELAP trial if they had a clinical diagnosis of secondary peritonitis requiring emergency laparotomy. Peritonitis had to be caused by perforation or infection of a visceral organ, or ischemia/ necrosis of part of the gastrointestinal tract or postoperative peritoneal infection. An Acute Physiology And Chronic Health Evaluation (APACHE)-II score above 10 was required, as the preferred strategy for mild peritonitis (APACHE-II score $\leq 10$ ) is on-demand. Exclusion criteria included: age below 18 or above 80 ; peritonitis due to bowel perforation after endoscopy operated within 24 hours; abdominal infection due to indwelling dialysis (CAPD) catheter; acute pancreatitis; expected survival of less than 6 months due to disseminated malignancy; severe brain damage due to trauma or anoxia; imperative relaparotomy (gauze packing).

To be eligible for participation in the present HR-QoL study, patients had to be alive and out of hospital at six months following index laparotomy (Figure 1).

\section{Instruments}

HR-QoL was assessed approximately six months after the index laparotomy by administering the patient self-report Euroqol 5-Dimensions (EQ-5D) question which includes five dimensions and the Euroqol-Visual Analogue Scale (EQ-VAS) [21]. The Euroqol instruments have been extensively validated, including Dutch healthy individuals, and were recently recommended as the instrument of choice in critical care studies [22-25]). EQ-5D was originally designed to complement other instruments but is now increasingly used as a 'stand alone' measure.

The EQ-5D measures five health dimensions: mobility (MO), self-care (SC), daily activities (DA), pain/discomfort (PD), and mood (MD) consisting of both anxiety and

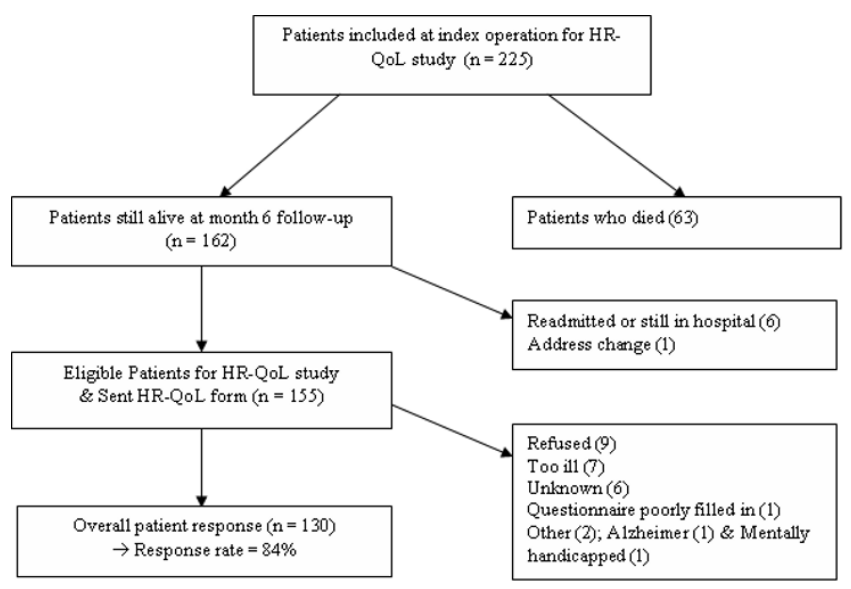

Figure I

Flowchart summarizing inclusion and response. 
depression. In the EQ-5D patients report: 0 (no problems), 1 (moderate problems), and 2 (extreme problems) [26]. Whilst the EQ-VAS is a thermometer-like scale, in which patients rate their overall well-being from 0 (worst imaginable overall health) to 100 (best imaginable overall health) $[26,27]$.

\section{Data collection}

Preoperative risk factors and postoperative morbidity data were prospectively collected for all eligible patients. HRQoL data were collected six months after index operation. EQ-5D and EQ-VAS questionnaires were sent by mail to patients who survived at least six months, with a reminder by phone within two weeks if there was no response. After one month without response patients were phoned and then new set of questionnaires with a reminder letter were sent.

\section{Reference populations}

We used measured with the same instrument for a sample of 851 healthy residents in the Netherlands as a reference population [18].

\section{Data analysis \\ Reference populations}

The proportion of peritonitis patients reporting moderate or extreme problems (combined together) on each of the EQ-5D dimensions in the study group was compared to the proportion reported by the general Dutch population using a $\chi^{2}$ tests. Differences in mean EQ-VAS scores were calculated between the study peritonitis patients and the general population stratified by 10 -year age groups, and tested for significance using the Student's t-test [26].

Representatively of the sample with HR-QoL measurements for the non-responders (non-respondent analysis) was evaluated using $\chi^{2}$ tests to compare categorical data, and the Student's t-test or the Mann-Whitney U test for continuous data.

\section{Predictive factors}

An initial set of potential factors was based on two previous studies examining factors associated with increased mortality and morbidity in patients with secondary peritonitis $[5,13]$. These candidate factors were divided into three distinct categories:

1) General patient characteristics: age, gender, and having one or more major comorbidities. Major comorbidities were measured by severity and included cardiovascular disease; chronic obstructive pulmonary disease (COPD); malignancy; renal disease, and diabetes mellitus (DM).

2) Peritonitis characteristics: severity of disease at study entry measured by the APACHE-II score and severity of peritonitis measured by the Mannheim Peritonitis Index (MPI), extent (localized versus diffuse) and type of contamination (clear, turbid, purulent, fecal), etiology of peritonitis (inflammation, perforation, ischemia/necrosis, anastomotic leakage), and community-acquired versus hospital-acquired or nosocomial infection, (these infections include post-operative peritonitis as complication of a previous (elective) surgical intervention or peritonitis that is the result of treatment in a hospital or hospital-like setting)

3) Postoperative characteristics: number of relaparotomies, length of stay in ICU and hospital, duration of mechanical ventilation, complications during ICU stay, i.e., acute respiratory distress syndrome (ARDS). Also factors including having an enterostomy at six months, the number of hospital readmissions (for peritonitis-related morbidity) and experiencing one of the predefined severe morbidities during the six-month follow-up (including incisional hernia, bowel obstruction/herniation, burst abdomen, abdominal compartment syndrome, fistula, intra-abdominal bleeding, perforation, anastomotic leakage, ischemia/necrosis, enterostomy dysfunction, bleeding ulcer, abscess (needing drainage), renal failure, myocardial infarction/embolus/cerebral vascular accident, pneumonia or urosepsis needing readmission (see Appendix 2 for the complete list)).

We used a general linear model to identify factors associated with the EQ-VAS, or with the proportion of patients reporting moderate or severe problems on either of the five dimensions of the EQ-5D. Factors associated with HR-QoL ( $\mathrm{p}<=0.1$ ) were then entered in a multivariate model, unless predictive factors were strongly correlated with each other, then only one factor with the strongest association was chosen. The functional form of continuous predictors was graphically assessed and, in the case of pertinent non-linearity, a transformation was performed.

Statistical Package for the Social Sciences (SPSS 11.01, SPSS Inc, Chicago, IL) was used for all data analysis.

\section{Results}

A total of 155 surviving patients were eligible for the HRQoL study and questionnaires were sent to all of them. The overall response rate was $85 \%$ (130/155; see Figure $1)$. The average responses were provided at 6 months and 4 days after index laparotomy.

The mean age of patients at enrollment was 63 years, and $53 \%$ of the patients were male (Table 1). Patients at trial entry were generally severely ill, as reflected by a mean APACHE-II score of 15.1 and mean MPI of 19.9 (Table 1). 
Table I: General patient, peritonitis and post-operative characteristics $(n=130)$

\begin{tabular}{|c|c|c|}
\hline $\begin{array}{l}\text { Patient Characteristics }(n= \\
\text { 130) }\end{array}$ & & Percentage \\
\hline Age; mean (SD) & $63(14)$ & \\
\hline Males; $\mathrm{n}$ & 70 & 53 \\
\hline$\geq \mathrm{I}$ major comorbidity; $\mathrm{n}$ & 73 & 56 \\
\hline \multicolumn{3}{|l|}{ Peritonitis Characteristics } \\
\hline APACHE - II mean (SD) & $15.1(4.1)$ & \\
\hline $\begin{array}{l}\text { Mannheim peritonitis index, mean } \\
\text { (SD) }\end{array}$ & $19.9(7.6)$ & \\
\hline \multicolumn{3}{|l|}{ Extent of contamination: } \\
\hline I or 2 quadrants & 49 & 37 \\
\hline Diffuse & 82 & 64 \\
\hline \multicolumn{3}{|l|}{ Type of contamination: } \\
\hline Clear & 8 & 6 \\
\hline Turbid & 29 & 22 \\
\hline Purulent & 42 & 32 \\
\hline \multicolumn{3}{|l|}{ Etiology of peritonitis: } \\
\hline Inflammation & 6 & 5 \\
\hline Perforation & 72 & 55 \\
\hline Ischemia/necrosis & 6 & 5 \\
\hline Anastomotic leakage & 41 & 31 \\
\hline Other & 6 & 5 \\
\hline $\begin{array}{l}\text { Hospital-acquired peritonitis } \\
\text { patients (peritonitis following } \\
\text { earlier elective operation and/or } \\
\text { during hospital stay) }\end{array}$ & 69 & 53 \\
\hline \multicolumn{3}{|l|}{ Postoperative Characteristics } \\
\hline Pts with $\geq$ I relaparotomy $n$ & 86 & 66 \\
\hline Relaparotomies; median (range) & 1.0 relaps $(1-10)$ & \\
\hline Pts admitted to ICU n & 115 & 88 \\
\hline $\begin{array}{l}\text { Length of ICU stay; median } \\
\text { (P25-P75) }\end{array}$ & 9 days $(6-2 I)$ & \\
\hline Patients ventilated $\mathrm{n}$ & 110 & 84 \\
\hline $\begin{array}{l}\text { Duration of ventilation; median, } \\
\text { (P25-P75) }\end{array}$ & 6 days $(3-12)$ & \\
\hline $\begin{array}{l}\text { Length of hospital stay median, } \\
\text { (P25-P75)§ }\end{array}$ & 34 days $(19-60)$ & \\
\hline $\begin{array}{l}\text { Acute Respiratory Distress } \\
\text { Syndrome (ARDS) }\end{array}$ & 7 & 5.4 \\
\hline $\begin{array}{l}\text { Patients readmitted } \geq 1 \text { at } 6 \\
\text { months }\end{array}$ & 74 & 57 \\
\hline $\begin{array}{l}\text { >1 Morbidities during 6-month } \\
\text { follow-up* }\end{array}$ & 33 & 26 \\
\hline $\begin{array}{l}\text { Patients with enterostomy at } 6 \\
\text { months }\end{array}$ & 73 & 56 \\
\hline
\end{tabular}

* Information on morbidities missing for one patient $(n=129)$ §For two patients the exact hospital stay was unknown, due to transfer to other hospital

There was no significant difference in any patient baseline characteristics; peritonitis characteristics or postoperative characteristics between patients who responded to the HR-QoL questionnaires $(\mathrm{n}=130)$ and patients that did not respond $(\mathrm{n}=32)$ (Figure 1$)$.

\section{Comparison with other populations}

Compared to a health reference population [18], the peritonitis group reported significantly more problems on all

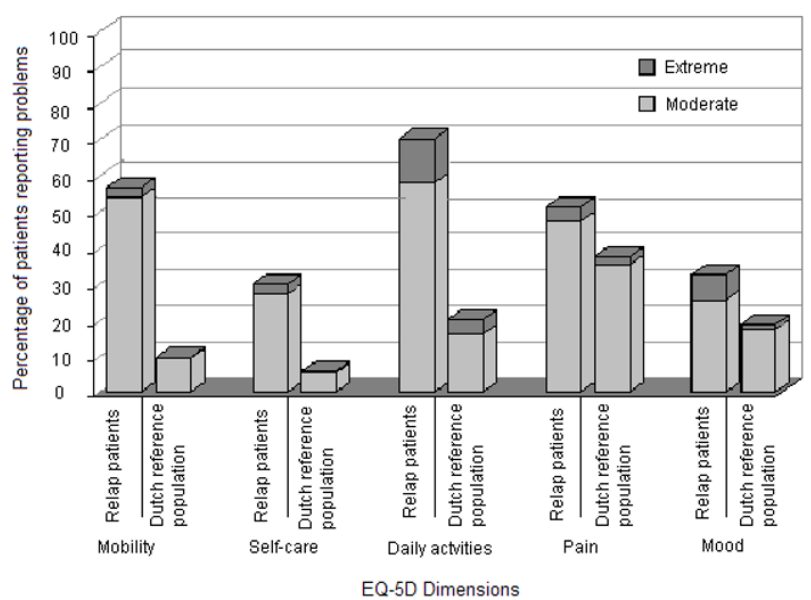

\section{Figure 2}

Percentage of HR-QoL problems reported by peritonitis study patients $(n=130)$ compared to a general reference population from The Netherlands (Dutch reference population) $(n=85 I)$ [I8] by EQ-5D dimensions.

EQ-5D dimensions ( $\mathrm{p}<0.001$ for all dimensions, see Figure 2). Patients with peritonitis showed in all age groups lower EQ-VAS scores than the reference group, indicating worse overall HR-QoL. In the RELAP group, EQ-VAS scores appeared to be low from young till old and did not particularly worsen for those who are older.

\section{Predictive factors}

Results of the univariate analyses evaluating patient, peritonitis and postoperative factors as predictors for HR-QoL at six months are reported in table 2 .

\section{General patient characteristics}

In a univariate analysis men reported significantly fewer problems with mobility and daily activities. Increasing age decreased overall well-being and increased problems in mobility, but was protective for mood problems with younger patients scoring more mood problems. Major comorbidities at baseline were predictive for more problems related to mobility and mood at six months (Table 2).

\section{Peritonitis characteristics}

Peritonitis characteristics were not associated with scores on EQ-VAS or EQ-5D when looking at severity of disease or peritonitis severity, etiology or type and extent of the contamination (Table 2). There were no HR-QoL differences between patients with community-developed peritonitis and patients with hospital-acquired peritonitis. 
Table 2: Strength of univariate association between potential predictors and reporting problems on the EQ-VAS and on the EQ-5D on which inclusion in final multivariate model is based.

\begin{tabular}{lllll} 
EQ-VAS & \multicolumn{3}{c}{ EQ-5D } & \\
\hline VAS & Mobility & Self-care & Daily Activity Pain Mood & $\begin{array}{c}\text { Included into } \\
\text { Multivariate model }\end{array}$
\end{tabular}

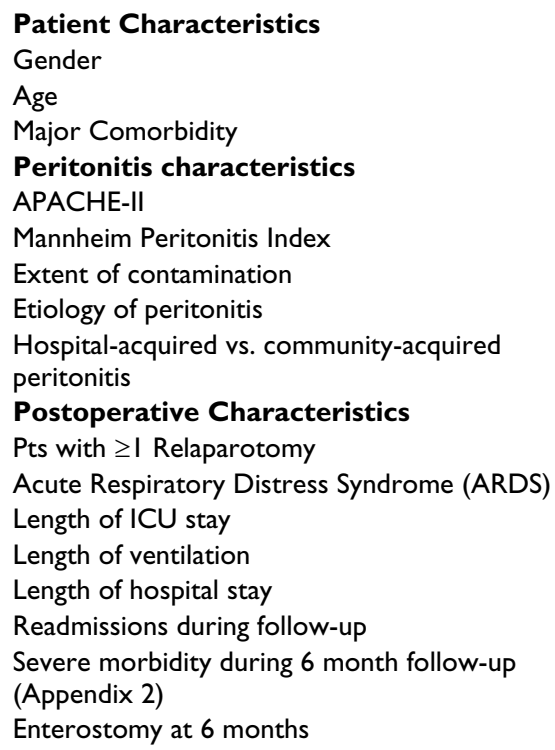

+ Univariate significance $(p<0.10),++$ univariate significance $<0.05$

- No univariate significance found

\section{Postoperative characteristics}

Patients who stayed longer in ICU and/or surgical hospital-ward reported more problems on all functional impairment dimensions mobility, self-care and daily activities and overall well-being, but not on the pain and mood dimensions (Table 2). Although ICU stay and hospital stay are clearly associated with HR-QoL, whilst in a univariate analysis mechanical ventilation was not.

Readmissions during the six-month follow-up were also associated with lower HR-QoL scores. Patients who still had an enterostomy six-months following surgery reported more problems in the functional impairment dimensions: mobility, self-care and daily activities (the combination these dimensions is often referred to as a specific discipline within HR-QoL called activities in daily life or ADL). Overall those patients reported more wellbeing problems than patients without an enterostomy (Table 2).

\section{Multivariate analysis}

The following factors were entered in the multivariate analysis based on the results of the univariate association ( $p \leq 0.10$ ) with HR-QoL with at least two of the five EQ$5 \mathrm{D}$ dimensions or an effect on the EQ-VAS (Table 2): gender, major comorbidity, enterostomy at six months, length of ICU stay and length of hospital stay (a log2 transformation was done to create linearity) and severe morbidity during follow-up. From the literature, it was decided that age should always be added to the models, irrespective of the univariate analyses [22,28-30]. ICU stay and hospital stay were highly correlated (Spearman's R = 0.681) and therefore not both of the factors could be added to the multivariate model. Length of hospital stay was selected to best represent the accumulation of what a patient underwent following secondary peritonitis, used as an adequate proxy for poor patients recovery and potential complications. The same set of factors were included in all six models (the EQ-VAS: Table 3 and the five EQ-5D dimensions: Table 4).

In the multivariate analysis the only independent factor that was predictive for poorer worse overall patient wellbeing, as measured by the EQ-VAS, was length of hospital stay (log2 transformed); every doubling of the length of hospital stay decreased the EQ-VAS (0-100) score by 3.8 points ( $\mathrm{p}=0.015$, Table 3$)$.

In the logistic models for each dimension of the EQ-5D the following factors were predictive of HR-QoL (Table 4). Females reported more mobility problems $(\mathrm{OR}=2.9, \mathrm{p}=$ 0.013 ), more problems in daily activities ( $\mathrm{OR}=3.7, \mathrm{p}=$ $0.006)$ and more pain and discomfort $(\mathrm{OR}=2.3, \mathrm{p}=$ $0.037)$. Increasing age was associated with fewer problems 
Table 3: Impact of potential predictors on EQ-VAS scores. Results expressed as absolute changes in mean scores derived from multivariate model.

\begin{tabular}{|c|c|c|}
\hline & \multicolumn{2}{|c|}{ Euroqol Visual Analogue Scale $(n=127 \ddagger)$} \\
\hline & Mean difference in EQ-VAS score $†$ & P-value \\
\hline Gender (Male vs. females) & 4.0 & 0.193 \\
\hline Age (per 10 years increase) & -2.9 & 0.348 \\
\hline Patients without major comorbidity at study entry & 3.9 & 0.192 \\
\hline Every doubling of the length of hospital stay & -3.8 & $0.015 *$ \\
\hline Patients without severe morbidity during six month follow-up & 6.4 & 0.077 \\
\hline Patients with no enterostomy at six months & 4.9 & 0.125 \\
\hline
\end{tabular}

* Significant $p<0.05$, bold

$\ddagger$ Three patients were dropped due to missing VAS scores

† Lower EQ-VAS scores indicate poorer health status

with $\operatorname{mood}(\mathrm{OR}=0.54$ per 10 years, $\mathrm{p}<0.001)$; whilst patients with a major comorbidity were more likely to report problems on the mood dimension $(\mathrm{OR}=3.6, \mathrm{p}=$ 0.007).

Length of hospital stay was associated with more problems in all ADL dimensions; a doubling of the length of hospital stay increased problems in mobility $(\mathrm{OR}=1.6, \mathrm{p}$ $=0.02)$, self-care $(\mathrm{OR}=2.5, \mathrm{p}<0.001)$ and daily activities $(\mathrm{OR}=1.9, \mathrm{p}=0.01)$. Whilst severe morbidity (as experienced) during the six months follow-up was no longer independently associated with lower HR-QoL in the multivariate model. However, longer hospital stay is in part due to severe morbidity; so clinically it may not be possible to consider them apart.

Patients with an enterostomy at six-month follow-up reported more problems for mobility $(\mathrm{OR}=2.8, \mathrm{p}=$ $0.016)$ and daily activities $(\mathrm{OR}=2.8, \mathrm{p}=0.027)$, but not for self-care or mood.

\section{Discussion}

This study shows that patients treated for secondary peritonitis report considerably more complaints on all EQ-5D dimensions six months after initial surgery than a general reference population. Furthermore, HR-QoL at six months was found to be associated with several patient characteristics and particularly postoperative characteristics, whereas factors directly related initial severity of peritonitis did not affect HR-QoL. [11].

\section{Comparisons with other populations}

The comparison with a general reference population of healthy individuals allows for a better understanding of the extent of reduction in HR-QoL in this patient group. To give an even better perspective of the extent of the HRQoL presented here we can compare our peritonitis patient group to a group of general sepsis patients, who were also measured at 6 months following ICU discharge using the Euroqol questionnaire [11]. Comparing these groups shows our peritonitis patients reported more problems with $\mathrm{ADL}$, e.g. more problems with mobility and

Table 4: Odds ratios for reporting moderate/severe problems on each of the dimensions of the EQ-5D. Results from multivariate model including all listed factors

\begin{tabular}{|c|c|c|c|c|c|c|c|c|c|c|}
\hline \multirow[t]{2}{*}{ Predictive Factors: } & \multicolumn{2}{|c|}{$\begin{array}{l}\text { Mobility } \\
(n=128)\end{array}$} & \multicolumn{2}{|c|}{$\begin{array}{l}\text { Self-care } \\
(n=129)\end{array}$} & \multicolumn{2}{|c|}{$\begin{array}{l}\text { Daily Activities } \\
\quad(n=129)\end{array}$} & \multicolumn{2}{|c|}{$\begin{array}{l}\text { Pain/Discomfort } \\
(n=129)\end{array}$} & \multicolumn{2}{|c|}{$\begin{array}{l}\text { Mood } \\
(n=130)\end{array}$} \\
\hline & OR & P-value & OR & P-value & OR & P-value & OR & P-value & OR & P-value \\
\hline Gender (Female) & 2.9 & $0.013 *$ & 1.5 & 0.296 & 3.7 & $0.006 *$ & 2.3 & $0.030 *$ & 1.7 & 0.176 \\
\hline Age (per 10 years increase) & 1.0 & 0.246 & 0.99 & 0.534 & 0.98 & 0.148 & 0.74 & 0.078 & 0.54 & $<0.001 *$ \\
\hline $\begin{array}{l}\text { Patients with major comorbidity at study } \\
\text { entry }\end{array}$ & 2.0 & 0.120 & 0.92 & 0.848 & 1.1 & 0.782 & 1.8 & 0.151 & 3.6 & $0.007 *$ \\
\hline Every doubling of the length of hospital stay & 1.6 & $0.020 *$ & 2.5 & $<0.001 *$ & 1.9 & $0.010 *$ & 1.1 & 0.537 & 0.91 & 0.649 \\
\hline $\begin{array}{l}\text { Patients with severe morbidity during six } \\
\text { month follow-up }\end{array}$ & 0.71 & 0.484 & 0.58 & 0.294 & 0.83 & 0.719 & 2.4 & 0.065 & 2.0 & 0.130 \\
\hline Patients with an enterostomy at six months & 2.8 & $0.016 *$ & 1.7 & 0.240 & 2.8 & $0.027 *$ & 1.2 & 0.613 & 1.5 & 0.320 \\
\hline
\end{tabular}

Significant $p<0.05$, bold

Patients report moderate and/or severe problems 
daily activities, despite having comparable APACHE-II scores, hospital stay and length of ICU stay with the general sepsis patients. This difference in ADL dimensions could, at least in part, be explained by some extent of disfiguration and protracted wound healing following major surgery for patients with peritonitis in contrast to patients with sepsis (resulting from other causes). As well, the peritonitis patients often have an enterostomy for a lengthy period of time, which in this study has also been shown to reduce patients' mobility and daily activities. In contrast, secondary peritonitis patients reported fewer mood problems than patients with sepsis from other causes. One possible factor that could account for this difference is the higher mean age of our peritonitis population. In this study and an earlier retrospective study we have shown that older secondary peritonitis patients report fewer mood problems [11,31].

\section{Factors associated with lower HR-QoL}

In our study, general patient characteristics played an important role in the HR-QoL at 6 months follow-up. Female patients were more likely to report problems with overall HR-QoL, mobility, daily activities, pain and discomfort and mood. Of the nine studies, involving survivors of critical illness and intensive care patients as reviewed by Dowdy et al. [20], associations between HRQOL and gender were found in only two studies $[32,33]$.

Peritonitis patients showed a clear association between increased age and improved emotional health, possibly related to an adjusting process. Similar findings were reported in other studies, showing that elderly patients demonstrated more positive health attitudes than younger survivors $[11,22,30,31]$. However, in a recent review no significant associations were found between age and mental health (SF-36), anxiety/depression (EQ-5D) and/or psychosocial QoL [20].

Comorbidity, often an important determinant of health outcomes, was frequently present in this patient group. Patients with 1 or more major comorbidity reported significantly more moods problems. In these analyses we only considered major comorbidities, indicating a preexistent more severely compromised clinical condition. Although, most patients also suffered from an underlying disease (i.e., primary condition) or underwent a primary procedure prior to their secondary peritonitis, these factors were not considered in major comorbidities. Primary conditions are more likely to be the actual cause or part of the etiology of the peritonitis than is an actual comorbidity; these included malignancy, diverticulitis, Crohn's disease, ulceritis and colitis ulcerosa. Disease severity measure by the APACHE-II has been shown to be an adequate predictor for survival in abdominal sepsis patients [2,5,33-35]. Studies relating disease severity with HR-
QOL studies have found mixed results; in some papers preoperative severity of disease was a predictor of HR-QoL [30,33,36-40], whilst others observed no correlation $[28,29,41-43]$. In our study higher APACHE scores were not associated with poorer HR-QoL. This absent relation could be explained by the homogeneity of the sample with respect to disease severity; only APACHE-II scores higher than 10 were included in the study, reflecting severe illness with an expected mortality around 30\% [35]. In this spectrum of severe illness the variability in APACHE-II might be insufficient to predict future HRQoL.

We found no relation between initial peritonitis severity (MPI), extent or type of contamination and the etiology of the peritonitis and HR-QoL at six months. This indicates that the HR-QoL outcome of the most severe peritonitis patients may in some cases be far better than anticipated during the initial phase. For example, if a peritonitis patient is admitted to the ICU with a high MPI score and has a diffuse fecal peritonitis then, conditional on survival, their HR-QoL at 6 months follow-up may be similar to those patients that were admitted with less severe peritonitis. This indicates that although these factors are indicators of mortality and morbidity, by themselves they are not associated with poorer HR-QoL at 6 months. As well, HR-QoL differences were not found between patients with community-developed peritonitis and patients with nosocomial peritonitis.

In this study the strongest factor associated with lower HR-QoL was length of hospitalization. This suggests that an extended and more complicated course of disease with longer ICU stay combined with severe morbidity accumulates into worse quality of life, most notably in problems with mobility, self-care, and daily activities. ADL problems were primarily related to an extended course of disease encountered during the hospital stay with longer ICU stay - likely related to an accumulation of factors, for example more severe organ dysfunction, such as ARDS, MOF, septic shock and critical illness neuropathy and depended on the patients' response to peritonitis - rather than the underlying etiology and extent of the peritonitis at presentation.

Contrary to expectations, experiencing disease-related morbidity during the six-month follow-up on its own was not an independent predictor for EQ-5D or EQ-VAS outcomes. This is partially due to the multivariate nature of our analysis, where length of hospital probably includes ICU stay in what it measures. Findings in the literature on the relation between length of hospital or length of ICU stay and HR-QoL vary: some studies also found that length of stay was strongly related to HR-QoL 
$[22,29,30,33,40]$, while other studies found no relation $[20,44]$.

Another particular sequel of the disease is having an enterostomy constructed at surgery for peritonitis, which in these patients is usually still present at six months followup. As expected, patients with an enterostomy reported more problems with mobility and daily activities. Reduction of the length of time until restoring continuity in those with a temporary enterostomy, as well as being more liberal with primary anastomosis in some situations (i.e., diverticulitis) may improve long-term HR-QoL.

We assessed HR-QoL using a generic questionnaire, which enabled us to make comparisons to the general population and other diseases populations [22]. The EQ-5D and EQ-VAS have also been recommended as the choice of generic HR-QoL patient groups, and well validated. Nonetheless, applying a disease-specific questionnaire, including peritonitis specific symptoms and complaints, may allow for more insight into possible factors that may not be detected by a generic HR-QoL instrument $[24,45]$.

It may be a viable option that hospitals consider investing into a tailored support network for patients with more lengthy hospitalization stays, to better prepare both the patient and the home caregivers for the period following discharge characterized by diminished HR-QoL. Younger patients of working age and patients with existing major comorbidity seem to warrant more psychosocial support when discharged from the hospital, which could in turn enable them to return to the workforce more quickly and reduce costs due to loss of productivity. Once the acute life-threatening situation has dissipated and patients are in the surgical ward or have been discharged there may be ample opportunities to consider the patients' psychosocial network. The results also suggest that this support should be aimed at all peritonitis patients, irrespective of their severity of illness at presentation, since their at six months HR-QoL is not different from those with a seemly more favorable presentation, as severity of peritonitis is not an important indicator of later HR-QoL.

\section{Authors' contributions}

$\mathrm{MB}, \mathrm{KB}, \mathrm{CdB}$ andOvR conceived the study. KB and OvRcoordinated the study. JB and MS participated in its design and aided in the statistical analysis. $\mathrm{BO}, \mathrm{MS}$ and EAR participated in the coordination and data analysis. $\mathrm{MB}, \mathrm{OvR}$, CM, HG, PdG, EH, MG and EPS were responsible for patient inclusion. All authors read and approved the final manuscript. The Dutch Peritonitis Study Group (Appendix 1) participated in the design and coordination of the study and was responsible for patient inclusion.

\section{Appendix I}

RELAP trial clinical centers and investigators of the Dutch Peritonitis Study Group (from the Department of Surgery, Academic Medical Center Amsterdam, The Netherlands).

All investigators are from Departments of Surgery unless specified (E) Clinical Epidemiology and Biostatistics (E) or (I) Intensive Care or Medical Psychology (MP).

O van Ruler, KR Boer (E), JB Reitsma (E), CW Mahler, EA Reuland, JWO van Till, BC Opmeer (E), PMM Bossuyt (E), MJ Schultz (I), MA Sprangers (MP), H Obertop, DJ Gouma, CAJM de Borgie (E), MA Boermeester, Academic Medical Center, Amsterdam; EPh Steller, P. Tanis, H Hart (I), St Lucas Andreas Hospital, Amsterdam; MF Gerhards, M Guijt, HM Oudemans (I), Onze Lieve Vrouwe Gasthuis, Amsterdam; K. Bosscha, E Ritchie, M Vermeer, Bosch Medical Centre, Den Bosch, The Netherlands. PW de Graaf, B van Etten, C Haazer, E Salm (I), Reinier de Graaf Hospital, Delft; B Lamme, EJ Hesselink, H Rommes (I), Gelre Hospital, Apeldoorn; RJ Oostenbroek, L te Velde, G Govaert, HH Ponssen (I), Albert Schweitzer Hospital, Dordrecht; HG Gooszen, MK Dinkelman, LPH Leenen (I), University Medical Centre Utrecht; EGJM Pierik, KWW Lansink, J Bakker (I), Isala Clinics, Zwolle;

Key staff and steering committee at coordinating center (AMC Amsterdam) RELAP trial:

O van Ruler (study coordinator and investigator), EA Reuland (data management), CW Mahler (investigator), JB Reitsma (epidemiologist), CAJM de Borgie (epidemiologist), KR Boer (quality of life investigator), BC Opmeer (economist), MA Boermeester (surgeon, supervisor, project leader) from the Department of Surgery, Academic Medical Center Amsterdam, The Netherlands.

\section{Appendix 2: Disease-related morbidity}

Non-surgical or conservative treatment of:

- Fistula (non-anatomical connection between hollow organ and cutis or between two hollow organs)

- Wound dehiscence/incisional hernia (full thickness discontinuity in abdominal wall with bulging of abdominal content) with obstruction

- Abscess needing percutanous drainage (pus-containing non-pre-existing cavity confirmed by positive Gramstain or culture)

- Renal failure (urine production $<500 \mathrm{cc} / 24 \mathrm{~h}$ with rising level of blood urea and creatinin) combined with dehydration (decreased circulating volume with raised hematocrit needing intravenous rehydration) based on 
inadequate oral intake and/or nausea/vomiting. Only when needing readmission.

- Myocardial infarction (ECG and enzyme changes being suggestive of MI, needing admission to CCU) or pulmonary embolus(ventilation perfusion mismatch on lung scintigraphy) or cerebrovascular accident (ischaemic or non ischaemic with persistent paresis or paralysis without previous history

- Gastric or duodenal bleeding (needing endoscopic treatment or embolisation therapy)

- Respiratory failure (due to pneumonia, pleural effusion or pulmonary edema needing oxygen therapy or mechanical ventilation)

- Urosepsis (urinary tract infection with positive urine and blood cultures and circulatory shock)

\section{$\underline{\text { Surgical intervention for disease-related morbidity }}$}

- Incisional hernia (full thickness discontinuity in abdominal wall with bulging of abdominal contents with or without obstruction with disabling complaints interfering with daily activities, needing surgery)

- Bowel obstruction or herniation due to intra-abdominal adhesions (diagnosis must be confirmed during surgery)

- Burst abdomen (complete midline or transverse discontinuity in abdominal wall)

- Abdominal compartment syndrome (intra-abdominal hypertension $>25 \mathrm{mmHg}$ with tense abdomen and with increasing respiratory and/or renal failure; measured by the urinary bladder pressure method (modified Burch criteria)

- Fistula (non-anatomical connection between intestine and cutis or between two hollow organs needing surgery)

- Intra-abdominal bleeding (Only when septic bleeding after index laparotomy or relaparotomy or when surgical bleeding after relaparotomy but not after index laparotomy)

- Intraabdominal haematoma (needing surgical evacuation)

- Perforation (of visceral organ; confirmed at surgery)
- Anastomotic leakage (anastomotic leak on contrast imaging needing surgery or contrast enhanced CT confirmed at relaparotomy)

- Ischemia or necrosis of a visceral organ (critically reduced blood flow to an intra-abdominal organ causing tissue loss; confirmed at pathological examination)

- Enterostomy dysfunction (due to prolaps, stenosis or retraction)

- Gastric or duodenal ulcer bleeding (needing intervention of any type)

\section{Acknowledgements}

Financial support: Supported by the Dutch Organisation for Health Research and Development (ZonMW), The Hague, The Netherlands. Health Care Efficiency Program Grant number 945-02-028.

\section{References}

I. Christou NV, Barie PS, Dellinger EP, Waymack JP, Stone HH: Surgical Infection Society intra-abdominal infection study. Prospective evaluation of management techniques and outcome. Arch Surg 1993, I 28:193-198.

2. Koperna T, Schulz F: Prognosis and treatment of peritonitis. Do we need new scoring systems? Arch Surg 1996, I3 I: 180-I86.

3. Wittmann DH, Schein M, Condon RE: Management of secondary peritonitis. Ann Surg 1996, 224:10-18.

4. Haraldsen P, Andersson R: Quality of life, morbidity, and mortality after surgical intensive care: a follow-up study of patients treated for abdominal sepsis in the surgical intensive care unit. Eur J Surg Suppl 2003:23-27.

5. Lamme B, Boermeester MA, Belt EJ, van Till JW, Gouma DJ, Obertop $\mathrm{H}$ : Mortality and morbidity of planned relaparotomy versus relaparotomy on demand for secondary peritonitis. $\mathrm{Br} J$ Surg 2004, 9 1:1046-1054.

6. Slade E, Tamber PS, Vincent JL: The Surviving Sepsis Campaign: raising awareness to reduce mortality. Crit Care 2003, 7:1-2.

7. Quartin AA, Schein RM, Kett DH, Peduzzi PN: Magnitude and duration of the effect of sepsis on survival. Department of Veterans Affairs Systemic Sepsis Cooperative Studies Group. JAMA 1997, 277:1058-1063.

8. Brun-Buisson C, Doyon F, Carlet J, Dellamonica P, Gouin F, Lepoutre A, Mercier JC, Offenstadt G, Regnier B: Incidence, risk factors, and outcome of severe sepsis and septic shock in adults. A multicenter prospective study in intensive care units. French ICU Group for Severe Sepsis. JAMA 1995, 274:968-974.

9. Pittet D, Rangel-Frausto S, Li N, Tarara D, Costigan M, Rempe L, Jebson $P$, Wenzel RP: Systemic inflammatory response syndrome, sepsis, severe sepsis and septic shock: incidence, morbidities and outcomes in surgical ICU patients. Intensive Care Med 1995, 2 I:302-309.

10. Alberti C, Brun-Buisson C, Goodman SV, Guidici D, Granton J, Moreno R, Smithies M, Thomas O, Artigas A, Le Gall JR: Influence of systemic inflammatory response syndrome and sepsis on outcome of critically ill infected patients. Am J Respir Crit Care Med 2003, I 68:77-84.

II. Granja C, Dias C, Costa-Pereira A, Sarmento A: Quality of life of survivors from severe sepsis and septic shock may be similar to that of others who survive critical illness. Crit Care 2004, 8:R91-R98.

12. Angus DC, Linde-Zwirble WT, Lidicker J, Clermont G, Carcillo J, Pinsky MR: Epidemiology of severe sepsis in the United States: analysis of incidence, outcome, and associated costs of care. Crit Care Med 2001, 29:1303-1310.

13. McLauchlan GJ, Anderson ID, Grant IS, Fearon KC: Outcome of patients with abdominal sepsis treated in an intensive care
unit. BrJ Surg 1995, 82:524-529. 
14. Bosscha K, Reijnders K, Jacobs MH, Post MW, Algra A, van der WC: Quality of life after severe bacterial peritonitis and infected necrotizing pancreatitis treated with open management of the abdomen and planned re-operations. Crit Care Med 200I, 29:1539-1543

15. Sloan JA, Cella D, Frost MH, Guyatt G, Osoba D: Quality of life III: translating the science of quality-of-life assessment into clinical practice-an example-driven approach for practicing clinicians and clinical researchers. Clin Ther 2003, 25 Suppl D:DI-D5.

16. Scheingraber S, Kurz T, Dralle H: Short- and long-term outcome and health-related quality of life after severe peritonitis. World J Surg 2002, 26:667-67I.

17. Juergensen $\mathrm{PH}$, Juergensen DM, Wuerth DB, Finkelstein $\mathrm{SH}$, Steele TE, Kliger AS, Finkelstein FO: Psychosocial factors and incidence of peritonitis. Adv Perit Dial 1996, I2:196-198.

18. Essink-Bot ML, Stouthard ME, Bonsel G]: Generalizability of valuations on health states collected with the EuroQolc-questionnaire. Health Econ 1993, 2:237-246.

19. Brooks R, Kerridge R, Hillman K, Bauman A, Daffurn K: Quality of life outcomes after intensive care. Comparison with a community group. Intensive Care Med 1997, 23:58I-586.

20. Dowdy DW, Eid MP, Sedrakyan A, Mendez-Tellez PA, Pronovost PJ, Herridge MS, Needham DM: Quality of life in adult survivors of critical illness: A systematic review of the literature. Intensive Care Med 2005, 3 I:6 I I-620.

21. Slevin ML, Plant H, Lynch D, Drinkwater J, Gregory WM: Who should measure quality of life, the doctor or the patient? $\mathrm{Br}$ J Cancer 1988, 57:109-112.

22. Badia X, Diaz-Prieto A, Rue M, Patrick DL: Measuring health and health state preferences among critically ill patients. Intensive Care Med 1996, 22:1379-1384.

23. Angus DC, Carlet J: Surviving intensive care: a report from the 2002 Brussels Roundtable. Intensive Care Med 2003, 29:368-377.

24. Brooks R, Rabin R, de Charro F, (Eds): The Measurement and Valuation of Health Status using EQ-5D: A European Perspective; Evidence from the EuroQol BIOMED Research Programme Edited by: Brooks R, R R and de Charro F. Dordrecht, Kluwer Academic Publishers; 2003.

25. EQ-5D, An instrument to describe and value health. 2007 [http://www.eurogol.org]. This website contains information about the EuroQol Group, membership and research activities, details of EQ-5D development and current status.

26. Roset M, Badia X, Mayo NE: Sample size calculations in studies using the EuroQol 5D. Qual Life Res 1999, 8:539-549.

27. Brooks R: EuroQol: the current state of play. Health Policy 1996 37:53-72.

28. Hurel D, Loirat P, Saulnier F, Nicolas F, Brivet F: Quality of life 6 months after intensive care: results of a prospective multicenter study using a generic health status scale and a satisfaction scale. Intensive Care Med 1997, 23:331-337.

29. Tian ZM, Miranda DR: Quality of life after intensive care with the sickness impact profile. Intensive Care Med 1995, 21:422-428.

30. Rockwood K, Noseworthy TW, Gibney RT, Konopad E, Shustack A, Stollery D, Johnston R, Grace M: One-year outcome of elderly and young patients admitted to intensive care units. Crit Care Med 1993, 21:687-69।.

31. Boer KR, Mahler CW, Unlu C, Lamme B, Vroom MB, Sprangers MA, Gouma DJ, Reitsma JB, De Borgie CA, Boermeester MA: Long-term prevalence of posttraumatic stress disorder symptoms in patients after secondary peritonitis. Crit Care 2007, I I:R30.

32. Badia X, Diaz-Prieto A, Gorriz MT, Herdman M, Torrado H, Farrero E, Cavanilles JM: Using the EuroQol-5D to measure changes in quality of life 12 months after discharge from an intensive care unit. Intensive Care Med 200I, 27:190I-I907.

33. Garcia-Lizana F, Peres BD, De Cubber M, Vincent JL: Long-term outcome in ICU patients: what about quality of life? Intensive Care Med 2003, 29:1286-1293.

34. Koperna T, Semmler D, Marian F: Risk stratification in emergency surgical patients: is the APACHE II score a reliable marker of physiological impairment? Arch Surg 200I, 136:55-59.

35. Bohnen JM, Mustard RA, Oxholm SE, Schouten BD: APACHE II score and abdominal sepsis. A prospective study. Arch Surg 1988, 123:225-229.

36. Wehler M, Geise A, Hadzionerovic D, Aljukic E, Reulbach U, Hahn EG, Strauss R: Health-related quality of life of patients with multiple organ dysfunction: individual changes and comparison with normative population. Crit Care Med 2003, 31:1094-II0I.

37. Granja C, Teixeira-Pinto A, Costa-Pereira A: Quality of life after intensive care--evaluation with EQ-5D questionnaire. Intensive Care Med 2002, 28:898-907.

38. RM Kleinpell: Exploring outcomes after critical illness in the elderly. Outcomes Manag 2003, 7:159-169.

39. Vedio AB CS Warburton FG,Griffiths MP,Leach RM,Treacher DF: Assessment of survival and quality of life after discharge from a teaching hospital general intensive care unit. Clin Intensive Care 2000, I I:39-46.

40. Pettila V, Kaarlola A, Makelainen A: Health-related quality of life of multiple organ dysfunction patients one year after intensive care. Intensive Care Med 2000, 26: |473-1479.

4I. Graf J, Koch M, Dujardin R, Kersten A, Janssens U: Health-related quality of life before, I month after, and 9 months after intensive care in medical cardiovascular and pulmonary patients. Crit Care Med 2003, 31:2163-2169.

42. Kvale $\mathrm{R}$, Flaatten $\mathrm{H}$ : Changes in health-related quality of life from 6 months to 2 years after discharge from intensive care. Health Qual Life Outcomes 2003, I:2

43. Sage WM, Rosenthal MH, Silverman JF: Is intensive care worth it? An assessment of input and outcome for the critically ill. Crit Care Med 1986, 14:777-782.

44. Stricker KH, Cavegn R, Takala J, Rothen HU: Does ICU length of stay influence quality of life? Acta Anaesthesiol Scand 2005, 49:975-983.

45. Dowie J: Decision validity should determine whether a generic or condition-specific HRQOL measure is used in health care decisions. Health Econ 2002, I I:I-8.
Publish with Biomed Central and every scientist can read your work free of charge

"BioMed Central will be the most significant development for disseminating the results of biomedical research in our lifetime. "

Sir Paul Nurse, Cancer Research UK

Your research papers will be:

- available free of charge to the entire biomedical community

- peer reviewed and published immediately upon acceptance

- cited in PubMed and archived on PubMed Central

- yours - you keep the copyright
BioMedcentral 